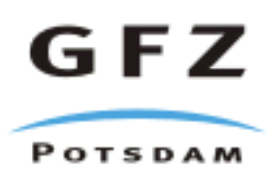

Originally published as:

Motagh, M., Walter, T. R., Sharifi, M. A., Fielding, E., Schenk, A., Anderssohn, J., Zschau, J. (2008): Land subsidence in Iran caused by widespread water reservoir overexploitation. Geophysical Research Letters, 35, L16403

DOI: 10.1029/2008GL033814. 


\title{
Land subsidence in Iran caused by widespread water reservoir overexploitation
}

\author{
Mahdi Motagh, ${ }^{1,2}$ Thomas R. Walter, ${ }^{1}$ Mohammad Ali Sharifi, ${ }^{2}$ Eric Fielding, ${ }^{3}$ \\ Andreas Schenk, ${ }^{4}$ Jan Anderssohn, ${ }^{5}$ and Jochen Zschau ${ }^{1}$ \\ Received 29 February 2008; revised 28 May 2008; accepted 20 June 2008; published 23 August 2008.
}

[1] The increasing demands upon groundwater resources due to expanding metropolitan and agricultural areas are a serious challenge, particularly in semiarid and arid regions. In Iran, decades of unrestrained groundwater extraction for domestic, agricultural, and industrial use have resulted in a precipitous depletion of this valuable resource. Here we show that the decline in groundwater levels is associated with land-surface deformation on local and regional scales. Combining water-level data with satellite radar observations provides evidence for the prevalence of compacting aquifers in the country. Groundwater level decline is often associated with destruction of the aquifers, which appears to be a common problem in the groundwater basins of central and northeast Iran. Global warming and future climate change will affect arid and semiarid areas in the coming decades, further augmenting hazards associated with groundwaterinduced land subsidence. Citation: Motagh, M., T. R. Walter, M. A. Sharifi, E. Fielding, A. Schenk, J. Anderssohn, and J. Zschau (2008), Land subsidence in Iran caused by widespread water reservoir overexploitation, Geophys. Res. Lett., 35, L16403, doi:10.1029/2008GL033814.

\section{Introduction}

[2] Geodetic measurement of groundwater-induced deformation is essential to understand hydrological processes affecting water reservoirs [Galloway et al., 1998; Bell et al., 2002; Hoffmann et al., 2003; Schmidt and Bürgmann, 2003]. The technique of Interferometric Synthetic Aperture Radar (InSAR) is uniquely suited to monitor elastic and inelastic response of aquifer systems to changes in groundwater levels, providing new insight into the role of geological structures and lithological parameters in plain aquifers [Amelung et al., 1999; Hoffmann et al., 2001; Bell et al., 2002; Motagh et al., 2007]. In contrast to other geodetic techniques that rely on point measurements at the Earth surface, InSAR readily provides high-resolution measurements $(\sim 20 \mathrm{~m} / \mathrm{pixel})$ of surface displacement at sub-cm accuracy over relatively large areas [Massonnet and Feigl,

\footnotetext{
${ }^{1}$ Department of Earthquake Risk and Early Warning, GeoForschungsZentrum, Potsdam, Germany.

${ }^{2}$ Department of Geomatics and Surveying Engineering, University of Tehran, Tehran, Iran.

${ }^{3}$ Jet Propulsion Laboratory, California Institute of Technology, Pasadena, California, USA.

${ }^{4}$ Geodetic Institute, Universität Karlsruhe, Karlsruhe, Germany

${ }^{5}$ Department of Remote Sensing, GeoForschungsZentrum, Potsdam, Germany.
}

1998; Bürgmann et al., 2000]. Although InSAR only measures one displacement component along the satellite line-of-sight direction, the latter is most sensitive to vertical motions, which is appropriate for measuring land subsidence or uplift above exploited or recharged aquifer systems.

[3] In this paper we present a survey of land subsidence due to water reservoir over-exploitation in Iran. Earlier geodetic studies detected localized subsidence in specific areas [Motagh et al., 2007]. Here, we show that land subsidence above exploited aquifers is in fact a very widespread phenomenon in Iran. We find evidence for the prevalence of compacting aquifers, resulting from excessive groundwater withdrawal, in turn causing this subsidence. The Envisat platform acquired radar images over major cities and valleys in Iran (Figure 1), for which we applied the two-pass method to derive differential interferograms [Massonnet et al., 1993]. The SAR data in this study are processed using the InSAR processing software SARscape (http://www.sarmap.ch). We remove the topographic component of interferometric measurements using a 90 m-posting digital elevation model [Farr and Kobrick, 2000]. The interferograms are filtered using a weighted power spectrum technique [Goldstein and Werner, 1998], unwrapped with the Snaphu software [Chen and Zebker, 2001] and converted from the phase delay in the line-of-sight direction into vertical changes between the two scenes, assuming that the slant line-of-sight range changes are dominated by vertical deformation alone. Figure 1 illustrates interferometric pairs depicting ground displacement in selected areas of major land subsidence-Tehran, Rafsanjan, Zarand-Kerman, Yazd-Ardakan, Kashmar, and Mashhad. The groundwater level measurements associated with some areas covered by the interferograms are shown in Figure 2.

\section{Areas of Subsidence Mapped by InSAR}

[4] We find that the area surrounding Tehran, the capital of Iran with a population of about 14 million people, is subject to groundwater-induced deformation (Figure 1a). Tehran's groundwater supply have been depleted over the past decades, partly due to uncontrolled immigration and rapid population growth, and partly due to increased extraction, for industry and farming activities spreading across the area [Sarraf et al., 2005]. Since the 1990's, extensive overexploitation of groundwater is evidenced by a fall of $\sim 13 \mathrm{~m}$ in groundwater level in the Varamin area to the southeast of the Tehran Plain (Figure 2). Official estimates claim that there are currently 8000 illegally drilled wells in the Tehran province, while the unofficial estimates put this figure closer to 30,000 (http://iran-daily.com/1384/2384/ $\mathrm{html} /$ panorama.htm\#s93396). The satellite data shows surface 

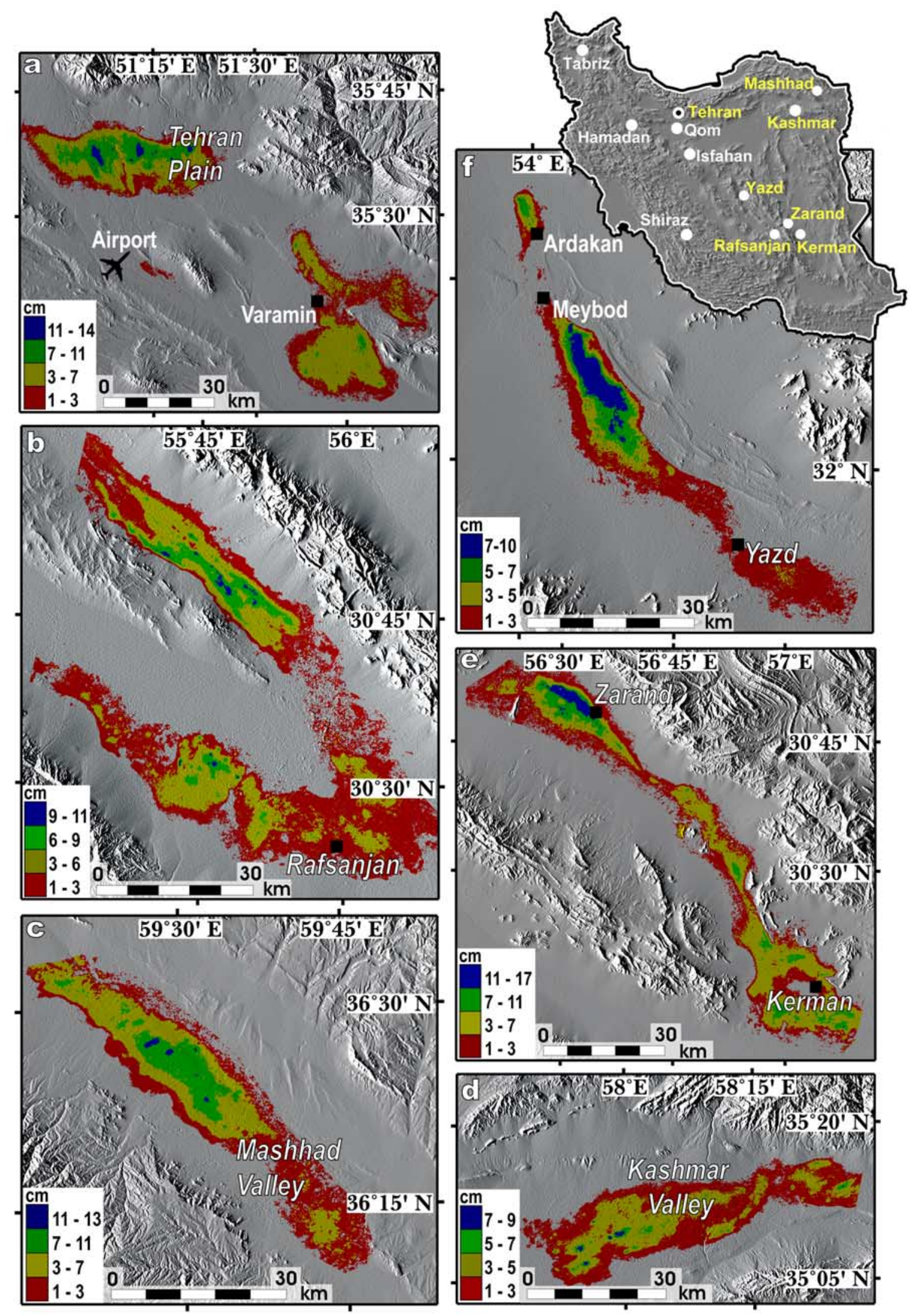

Figure 1 


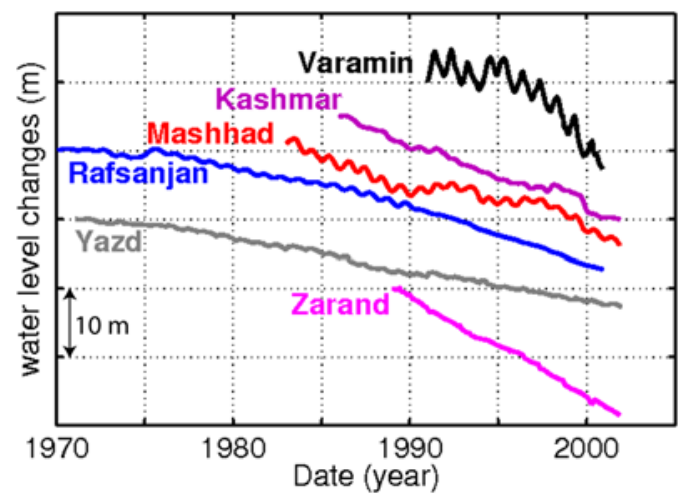

Figure 2. Graphs showing estimates of average groundwater level change resulting from increased withdrawal in Varamin, Rafsanjan, Mashhad, Kashmar, Yazd, and Zarand. The declining level curves are each based on a large number of piezometric water table records, thus providing average information on water level decline.

deformation in Tehran mainly occurs in two regions: one in the western part of the Tehran Plain and one in the Varamin area to the southeast of the Tehran Plain (Figure 1a). The subsidence feature in Western Tehran exhibits as much as $14 \mathrm{~cm}$ of subsidence for the 140-day time interval between 13 June and 31 October 2004 , which is $\sim 36 \mathrm{~cm} / \mathrm{yr}$ assuming a constant rate. The rate of subsidence is slower in Varamin, reaching a maximum of $9 \mathrm{~cm}$ for the June-October 2004 period $(\sim 23 \mathrm{~cm} / \mathrm{yr})$. The InSAR map also reveals a small subsiding zone located on the eastern side of the newly constructed Tehran International Airport to the southwest of Tehran City.

[5] Another area subject to subsidence is the Rafsanjan plain within central Iran (Figure 1b). Intensive groundwater extraction for irrigation [Mousavi et al., 2001], mainly pistachio production, has lowered regional groundwater levels by more than 15 meters between 1971 and 2001 (Figure 2). The area of surface deformation, as defined by the 70-day interferogram covering May 17, 2005 to July 26, 2005 (Figure 1b), delineates a broad plain-wide subsidence feature punctuated by local bowls exhibiting as much as $10 \mathrm{~cm}$ of subsidence $(\sim 50 \mathrm{~cm} / \mathrm{yr})$. The localized bowls are likely to be locations of more pumping in the plain.

[6] Exploitation of groundwater has also been very intensive in the valleys of Mashhad and Kashmar in the northeast of Iran, resulting in a decline of the mean groundwater levels by $15 \mathrm{~m}$ since the 1980's (Figure 2), reaching as much as $64 \mathrm{~m}$ over the past 4 decades in some places [Motagh et al., 2007; Anderssohn et al., 2008]. As shown in Figure 1c, the associated subsidence in Mashhad, the second largest metropolitan area in Iran (population 4 million), occurs as an elliptical-shaped bowl aligned NWSE along the axis of the valley with a maximum value of $\sim 12 \mathrm{~cm}$ for the 140-day period between June 14, 2004 and November 1, 2004 ( $30 \mathrm{~cm} / \mathrm{yr})$. In Kashmar, InSAR results (Figure 1d) indicate a significant subsidence bowl with a peak value of up to $8 \mathrm{~cm}$ for the 105-day period between August 26 and December 9, 2004 ( $\sim 27 \mathrm{~cm} / \mathrm{yr})$.

[7] The Zarand-Kerman plain to the northeast of Rafsanjan is also experiencing significant subsidence. The region has experienced a decline of groundwater levels by as much as $\sim 20 \mathrm{~m}$ since 1990 (Figure 2). Figure 1e illustrates a 245-day Envisat interferogram of the ZarandKerman Plain formed by InSAR images taken in July 3, 2003 and March 4, 2004. The interferogram indicates that an area of more than 1000 square kilometers in the valley is experiencing subsidence. The large subsidence feature, which extends $\sim 37 \mathrm{~km} \mathrm{NW-SE}$ and $\sim 10 \mathrm{~km} \mathrm{NE-SW}$, occurs around Zarand with a peak value of $\sim 15-17 \mathrm{~cm}$ for the 245-day period $(22-25 \mathrm{~cm} / \mathrm{yr})$. The areas around Kerman and the central part of the valley are also subsiding, but at a lesser rate, by as much as $9 \mathrm{~cm}$ in places during this period.

[8] Located in the center of Iran's desert area, the province of Yazd is among the driest regions in Iran with an average annual rainfall of only 60 millimeters [Motiee et al., 2006]. It relies heavily on groundwater supplies, which are delivered by tunnels (known regionally as Qanat) for irrigation and industrial needs. Groundwater level measurements for several piezometric wells show a steady decline of about $12 \mathrm{~m}$ since the 1970's. The interferogram of the Yazd-Ardakan Plain (Figure 1f), which spans 350 days from Sept 17, 2003 to Sept 1, 2004, delineates three areas of deformation that together form an arc-shaped area of $\sim 90 \mathrm{~km}$ from southeast of Yazd to north of Ardakan. The major subsidence feature lies between Yazd and Meybod, exhibiting as much as $9 \mathrm{~cm}$ of vertical deformation for the 350-day time period covered by the interferogram $(\sim 9.4 \mathrm{~cm} / \mathrm{yr})$.

\section{Discussion}

[9] The InSAR-derived subsidence maps presented in this study have important implications for the mitigation of land subsidence hazards in Iran and may help improve the management of groundwater resources at local and regional levels. Comparing InSAR-derived subsidence maps such as those shown in Figure 1 and Landsat TM images reveals that subsidence mainly affects agricultural

Figure 1. InSAR-derived subsidence maps showing groundwater-related deformation in 6 regions in Iran. (a) Tehran, time span: June 13, 2004-October 31, 2004 (140 d); (b) Rafsanjan, time span: May 17, 2005-July 26, 2005 (70 d); (c) Mashhad, time span: June 14, 2004-November 1, 2004 (140 d); (d) Kashmar, time span: August 26, 2004-December 9, 2004 (105 d); (e) Zarand-Kerman, time span: July 3, 2003-March 4, 2004 (245 d); (f) Yazd-Ardakan, time span: September 17, 2003-September 1, 2004 (350 d). Interferometric pairs are unwrapped, geocoded, converted from phase difference in radian to vertical displacements in centimeters, averaged over $100 \mathrm{x} 100 \mathrm{~m}$ bins, and overlain upon shaded relief topography, which was formed from 90 m-posting SRTM data. The upper inset shows the location of areas in Iran that were surveyed in this study using InSAR. Regions showing groundwater-induced deformation have been specified by yellow color. 
settings (auxiliary ${ }^{1}$ KML GoogleEarth files), demonstrating that groundwater pumping for agricultural activities is the major responsible for land subsidence in central and northeast Iran. Our study suggests that at least $25 \%$ of Iran's population of 70 million reside close to dramatically shrinking water reservoirs, where surface deformation has the potential to reach a meter or more within just a few years. Rapid subsidence due to groundwater pumping is also observed over smaller spatial scale. For example, overexploitation of aquifers in the Kerman province has caused a small subsiding zone with relatively high rates (up to $14 \mathrm{~cm} /$ yr) in an agricultural region $\sim 50 \mathrm{~km}$ southeast of Bam (auxiliary material Figure S1).

[10] Note that most of the interferograms investigated in this study cover summer seasons, hence they may show higher subsidence rates than full-year measurements. In fact, piezometric data show some seasonal fluctuations (Figure 2), that are expected to have some influence on the subsidence rate [Schmidt and Bürgmann, 2003]. InSAR pairs covering consecutive time periods or those that included rainy seasons (auxiliary material Figures $\mathrm{S} 2 \mathrm{a}-\mathrm{S} 2 \mathrm{f}$ ) also show subsidence, implying that the deformation is primarily controlled by inelastic, permanent compaction. Although the analysis of a few interferograms did not show significant seasonal variations in the subsidence rate in Mashhad between 2003 and 2005 [Motagh et al., 2007], more detailed studies based on InSAR time-series analysis are required to better assess the possibility of such variations in the displacement field over compacting aquifer systems, allowing further details of the structure and hydrogeologic parameters of a groundwater basin to be resolved [Freeze and Cherry, 1979; Hoffmann et al., 2001].

[11] In comparison to the rate of groundwater-induced deformation in other well-known basins such as Las Vegas, USA [Bell et al., 2002], Mexico City, Mexico [Poland and Davis, 1969] and New Orleans, USA [Dixon et al., 2006], Iran currently hosts some of the fastest sinking valleys and plain aquifers in the world. Hence, unregulated groundwater extraction and the associated subsidence in the future may also threaten non-agricultural regions, resulting in costly damage to infrastructure due to changing ground levels. While damage to infrastructure can be repaired, the impact of depleted groundwater supplies will be more insidious, with immense social, economic and environmental consequences. Future climate change is expected to put additional stress on ground water resources in Iran. Recent studies show that total water resources per capita in Iran have plunged by more than $65 \%$ during the last 4 decades, and are expected to decrease by another $16 \%$ by 2025 [Sarraf et al., 2005]. The increased demand for groundwater, and the high rate of subsidence resulting from overexploitation of this valuable resource are likely to become a serious challenge for future development at groundwater basins of central and northeast Iran.

[12] Experiences of other regions suffering from groundwater depletion and rapid subsidence show that implementing effective water resource management may help mitigate potential hazards posed by land surface subsidence. For example, importation of surface water to agricultural areas

\footnotetext{
${ }^{1}$ Auxiliary materials are available in the HTML. doi:10.1029/ 2008 GL033814.
}

in San Joaquin Valley in California via the California Aqueduct in the late 1960's sharply decreased deformation rates in regions that had previously experienced up to $10 \mathrm{~m}$ of subsidence [Ireland et al., 1984]. The area that is now the City of San Jose (in the Santa Clara Valley) also had rapid subsidence of up to $4 \mathrm{~m}$ until remedial action was taken to stop water withdrawal [Poland and Ireland, 1988] -InSAR measurements now show only seasonal cycles of $\sim 2 \mathrm{~cm}$ and an overall rebound of $\sim 5 \mathrm{~cm}$ in the Santa Clara Valley as water levels have been restored to near-artesian levels, thanks to reliance on water transported to the Bay Area from the Sierra Nevada Mountains [Schmidt and Bürgmann, 2003]. Careful monitoring of groundwater resources is therefore necessary and caution should be taken to properly use groundwater so as to reduce the socio-economic consequences of overexploitation, that might be felt across national boundaries. Finally, we point out the importance of acquiring detailed hydrological data such as well locations, exploitation rates and lithostratigraphic maps of subsurface sequence in areas affected by land subsidence to better understand the relation between surface displacements and the lowering of the groundwater level. Such information, coupled with continued monitoring using InSAR, has the potential of revealing further details of the hydrology of the areas of subsidence and the geomechanical parameters of the underlying aquifer structure.

[13] Acknowledgments. We thank Water Resources Management of Iran for providing piezometric data. M. M. gratefully acknowledges financial support from the German Research Foundation (MO 1851/1-1). Contribution of the National Cartographic Center of Iran (NCC) through the research project 10426 is also acknowledged. Part of the research described in this paper was carried out at the Jet Propulsion Laboratory (JPL), California Institute of Technology, under a contract with NASA. Envisat data were provided by the European Space Agency via category-1 proposals 2892 and 3740. We thank Kevin Fleming and Alan Levander for their comments on the earlier version of this manuscript. We also thank Roland Bürgmann, Pietro Teatini, and an anonymous reviewer for their thoughtful review of this paper and appreciate constructive comments by the Associate Editor.

\section{References}

Amelung, F., D. L. Galloway, J. W. Bell, H. A. Zebker, and R. J. Laczniak (1999), Sensing the ups and downs of Las Vegas: InSAR reveals structural control of land subsidence and aquifer-system deformation, Geology, 27(6), 483-486.

Anderssohn, J., H. L. Wetzel, T. R. Walter, M. Motagh, Y. Djamour, and H. Kaufmann (2008), Land subsidence pattern controlled by old alpine basement faults in the Kashmar Valley, northeast Iran: Results from InSAR and levelling, Geophys. J. Int., doi:10.1111/j.1365-246X.2008.03805.x, 174, 287-294.

Bell, J. W., F. Amelung, A. R. Ramelli, and G. Blewitt (2002), Land subsidence in Las Vegas, Nevada, 1935-2000: New geodetic data show evolution, revised spatial patterns, and reduced rates, Environ. Eng. Geosci., 8(3), 155-174.

Bürgmann, R., P. A. Rosen, and E. J. Fielding (2000), Synthetic aperture radar interferometry to measure Earth's surface topography and its deformation, Annu. Rev. Earth Planet. Sci., 28, 169-209.

Chen, C. W., and H. A. Zebker (2001), Two-dimensional phase unwrapping with use of statistical models for cost functions in nonlinear optimization, J. Opt. Soc. Am. A Opt. Image Sci., 18(2), 338-351.

Dixon, T. H., F. Amelung, A. Ferretti, F. Novali, F. Rocca, R. Dokka, G. Sella, S.-W. Kim, S. Wdowinski, and D. Whitman (2006), New Orleans subsidence: Space geodesy and Hurricane Katrina flooding, Nature, 441, $578-588$.

Farr, T. G., and M. Kobrick (2000), The Shuttle Radar Topography Mission produces a wealth of data, EOS Trans. AGU, 81, 583-585.

Freeze, R. A., and J. A. Cherry (1979), Groundwater, 604 pp., PrenticeHall, Upper Saddle River, N. J.

Galloway, D. L., K. W. Hudnut, S. E. Ingebritsen, S. P. Phillips, G. Peltzer, F. Rogez, and P. A. Rosen (1998), Detection of aquifer system compaction and land subsidence using interferometric synthetic aperture radar, 
Antelope Valley, Mojave Desert, California, Water Resour. Res., 34(10), 2573-2586.

Goldstein, R., and C. Werner (1998), Radar interferogram filtering for geophysical applications, Geophys. Res. Lett., 25, 4035-4038.

Hoffmann, J., H. A. Zebker, D. L. Galloway, and F. Amelung (2001), Seasonal subsidence and rebound in Las Vegas Valley, Nevada, observed by synthetic aperture radar interferometry, Water Resour. Res., 37(6), $1551-1566$

Hoffmann, J., D. L. Galloway, and H. A. Zebker (2003), Inverse modeling of interbed storage parameters using land subsidence observations, Antelope Valley, California, Water Resour. Res., 39(2), 1031, doi:10.1029/ 2001 WR001252.

Ireland, R. L., J. F. Poland, and F. S. Riley (1984), Land subsidence in the San Joaquin Valley, California, as of 1980, U.S. Geol. Surv. Prof. Pap., 437-I, 93 pp.

Massonnet, D., and K. L. Feigl (1998), Radar interferometry and its application to changes in the Earth's surface, Rev. Geophys., 36(4), $441-500$.

Massonnet, D., M. Rossi, C. Carmona, F. Adragna, G. Peltzer, K. Feigl, and T. Rabaute (1993), The displacement field of the Landers earthquake mapped by radar interferometry, Nature, 364, 138-142.

Motagh, M., Y. Djamour, T. R. Walter, H. U. Wetzel, J. Zschau, and S. Arabi (2007), Land subsidence in Mashhad Valley, northeast Iran; results from InSAR, levelling and GPS, Geophys. J. Int., 168(2), 518-526.

Motiee, H., E. Mcbean, A. Semsar, B. Gharabaghi, and V. Ghomashchi (2006), Assessment of the contributions of traditional Qanats in sustainable water resources management, Int. J. Water Resour. Dev., 22(4), $575-588$.
Mousavi, S. M., A. Shamsai, M. H. E. Naggar, and M. Khamehchian (2001), A GPS-based monitoring program of land subsidence due to groundwater withdrawal in Iran, Can. J. Civ. Eng., 28(3), 452-464.

Poland, J. F., and G. H. Davis (1969), Land subsidence due to withdrawal of fluids, in Reviews in Engineering Geology, vol. II, pp, 187-268, Geol. Soc. of Am., Boulder, Colo.

Poland, J. F., and R. L. Ireland (1988), Land subsidence in the Santa Clara Valley, California, as of 1982, U.S. Geol. Surv. Prof. Pap., 497, 61 pp.

Sarraf, M., M. Owaygen, G. Ruta, and L. Croitoru (2005), Islamic Republic of Iran: Cost assessment of environmental degradation, Tech. Rep. 32043 $I R$, World Bank, Washington, D. C.

Schmidt, D. A., and R. Bürgmann (2003), Time-dependent land uplift and subsidence in the Santa Clara Valley, California, from a large interferometric synthetic aperture radar data set, J. Geophys. Res., 108(B9), 2416, doi: $10.1029 / 2002 J B 002267$.

J. Anderssohn, Department of Remote Sensing, GeoForschungsZentrum (GFZ), D-14473 Potsdam, Germany. (calypso@gfz-potsdam.de)

E. Fielding, Jet Propulsion Laboratory, California Institute of Technology, Pasadena, CA 91109, USA. (eric.j.fielding@jpl.nasa.gov)

M. Motagh, T. R. Walter, and J. Zschau, Department of Earthquake Risk and Early Warning, GeoForschungsZentrum, Telegrafenberg Haus E, Sektion 2.1, Potsdam, D-14473 Germany. (motagh@gfz-potsdam.de; twalter@gfz-potsdam.de; zschau@gfz-potsdam.de)

A. Schenk, Geodetic Institute, Universität Karlsruhe, D-76131 Karlsruhe, Germany. (schenk@gik.uni-karlsruhe.de)

M. A. Sharifi, Department of Geomatics and Surveying Engineering, University of Tehran, Tehran, Iran. (sharifi@ut.ac.ir) 